\title{
Effect of Gefitinib Combined with Chemotherapy in Patients with Advanced NSCLC: A Retrospective Cohort Study
}

\author{
Lili Dai ${ }^{1, *}$ \\ Wei Wang ${ }^{2, *}$ \\ Wenli $\mathrm{Li}^{3}$ \\ $\mathrm{Ya} \mathrm{Wu} \mathrm{W}^{3}$ \\ Kaixin $\mathrm{Qu}^{2}$ \\ 'Department of Geriatrics, Funan \\ County People's Hospital, Fuyang, \\ People's Republic of China; ${ }^{2}$ Department \\ of Respiratory Medicine, Funan County \\ People's Hospital, Fuyang, People's \\ Republic of China; ${ }^{3}$ Department of \\ Respiratory Medicine, Fuyang Hospital, \\ Anhui Medical University, Fuyang, \\ People's Republic of China \\ *These authors contributed equally to \\ this work
}

Correspondence: Kaixin Qu Department of Respiratory Medicine, Funan County People's Hospital, No. 18, Santa Road, Funan County, Fuyang City, 236300, People's Republic of China Tel +86 I775580623।

Email qukaixin19770418@163.com
Background: There are currently no methods for the treatment of reversible drug-resistant EGFR-TKI lung cancer in the clinical setting, and thus, the patients finally return to the currently used drugs. This study aimed to compare the efficacy of chemotherapy alone and gefitinib combined with chemotherapy in the treatment of non-small cell lung cancer (NSCLC) patients in advanced stage with the mutation of epidermal growth factor receptor (EGFR).

Methods: A retrospective analysis was carried out on 120 patients with advanced EGFRm+ NSCLC who were divided into the control group (CG, received chemotherapy alone) or the observation group (OG, received chemotherapy and gefitinib) according to the treatment methods.

Results: Comparison of the objective response rates (ORRs) showed no statistical significant difference between OG (36.92\%) and CG (29.09\%, P > 0.05), whereas in OG, disease control rate (DCR) was significantly increased in comparison with $\mathrm{CG}(\mathrm{P}<0.05)$. The medians of progression-free survival (PFS) and overall survival (OS) in OG were 8.0 months and 24.0 months, respectively, which were longer than 5.0 months and 18.0 months in $\mathrm{CG}(\mathrm{P}$ $=0.031)$. The univariate analysis revealed that clinical stage of tumor $(\mathrm{HR}=1.590,95 \% \mathrm{CI}$ : 1.097-2.343) was the prognostic factor for advanced lung cancer. Multi-factor Cox regression analysis revealed that clinical analysis was an independent prognostic factor $(\mathrm{HR}=$ 1.701, 95\% CI: 1.099-2.632).

Conclusion: In PFS patients, the OS rate was significantly improved, which was worth for clinical use.

Keywords: advanced non-small cell lung cancer, NSCLC, anti-vascular therapy, prognosis

\section{Introduction}

Malignant tumor is the main disease threatening human health, among which lung cancer has become the most frequent malignancy. According to the US cancer statistics report, there were more than 224,000 new cases of lung cancer in the United States in 2016, with a death roll of more than 158,000 cases. ${ }^{1}$ Patients with respiratory system diseases accounted for $>90 \%$ of the population, posing a serious threat to their safety and life quality. ${ }^{2}$ According to biological characteristics, lung cancer can be mainly divided into non-small cell lung cancer (NSCLC) and small cell lung cancer. ${ }^{1}$ Statistics $^{3}$ show that NSCLC accounts for $>85 \%$ of the total number of lung cancers; among them, adenocarcinoma is the main type of NSCLC. In clinical practice, most patients do not have obvious abnormalities at the time of 
onset. When the disease worsens, patients are admitted to the hospital. At this time, the patient's condition has basically entered the advanced stage, and the best treatment opportunity is missed.

Chemotherapy can delay the onset of symptoms; however, the prognosis is relatively poor. ${ }^{4}$ Therefore, identifying new treatment methods is critical to improve the prognosis and quality of life of patients.

The main treatments for lung cancer in advanced stage include chemotherapy and other methods, which, however, have been proved to fail in prolonging the median of survival time. ${ }^{5}$ A previous study ${ }^{6}$ showed that first-line chemotherapy can only achieve a maximum efficiency of $40 \%$, the median survival time of patients can only be maintained at $8-10$ months, and only $40 \%$ of the patients can survive for 1 year. Moreover, first-line chemotherapy mainly uses double platinum drugs, and the main toxicity, side effects, and adverse reactions during the treatment are also significantly increased. ${ }^{7}$ Recently, molecular targeted therapy remains controversial in the treatment of lung cancer, although it has made some progress. As a main target drug for the treatment of advanced lung cancer, EGFRtyrosine kinase inhibitor (EGFR-TKI) inhibits EGFR signaling while promotes tumor cell apoptosis, inhibits proliferation, and prevents metastasis. ${ }^{8}$

The representative drug of EGFR-TKI is mainly gefitinib, a synthetic small-molecule quinazoline derivative that inhibits EGFR transmission by competing with adenosine triphosphate (ATP) in the body. ${ }^{9}$ A study ${ }^{10}$ showed that gefitinib can increase the disease control rate (DCR) to $77 \%$ and effectiveness to $35 \%$ in patients with advanced EGFRm+, and 1-year survival rate can attain nearly $60 \%$, with particularly obvious curative effect. However, any drug will lead to resistance over a long period of time, and patients treated with EGFR-TKI will also develop drug resistance. There are currently no methods for the treatment of reversible drug-resistant EGFR-TKI lung cancer in the clinical setting, and thus, the patients finally return to the currently used drugs.

NEJ009 study is the first randomized Phase III trial that compared gefitinib plus chemotherapy with gefitinib in patients with untreated NSCLC harboring EGFR mutations. This study compared the efficacy of chemotherapy alone and gefitinib combined with chemotherapy for advanced EGFRm+ NSCLC. The survival, toxicity, side effects, and risk factors of the patients were analyzed to provide reference for clinicians.

\section{Patients and Methods}

A retrospective analysis was performed on 120 NSCLC patients with advanced EGFRm+ admitted to Funan County People's Hospital from January 2019 to November 2019, and they were divided into the control group (CG, received chemotherapy alone) or the observation group (OG, received chemotherapy and gefitinib) according to the treatment methods (Figure 1). In CG, there were 55 patients comprising 40 males and 15 females, with an age range of 35-70 years and an average age of $62.5 \pm 6.4$ years, while in OG, there were 65 patients comprising 52 males and 13 females, with an age range of 30-69 years and an average age of $63.1 \pm 5.9$ years. The study was approved by the Medical Ethics Committee of Funan County People's Hospital, and patients and their families were informed of the study objective and provided signed informed consent.

The objective response rate (ORR), DCR, progressionfree survival (PFS), overall survival (OS) and the side effects of patients during the treatment were compared between the two groups.

\section{Inclusion and Exclusion Criteria}

Inclusion criteria: Patients who diagnosed with lung cancer by cytological and histological examination and confirmed with positive mutation by the EGFR gene test. According to the World Health Organization staging, the patient's pathological staging ${ }^{11}$ was stage III-IV, and the patient's clinical data were complete, with treatment and follow-up. Exclusion criteria: Patients with other malignant tumors, with congenital defects, with immunodeficiency, with severe liver and kidney function damage, with ECOG score of $>1$, those who were contraindicated to use this drug, and who had cognitive dysfunctions related with this drug were excluded from this study. A significant relationship was observed between the two groups.

\section{Treatment Method}

A total of 120 patients underwent the chemotherapy alone with the following methods: On the first day, pemetrexed $500 \mathrm{mg} / \mathrm{m}^{2}$ (Dezhou Deyao Pharmaceutical Co., Ltd., H20080230, specification: $0.5 \mathrm{~g}$ ) was infused intravenously, followed by intravenous infusion of cisplatin $25 \mathrm{mg} / \mathrm{m}^{2}$ (Jiangsu Hansoh Pharmaceutical Group Co., Ltd., H20040813 $6 \mathrm{~mL}$ : $30 \mathrm{mg} \times 1 /$ box) on the second, third, and fourth days, and then every 3 weeks as a course 


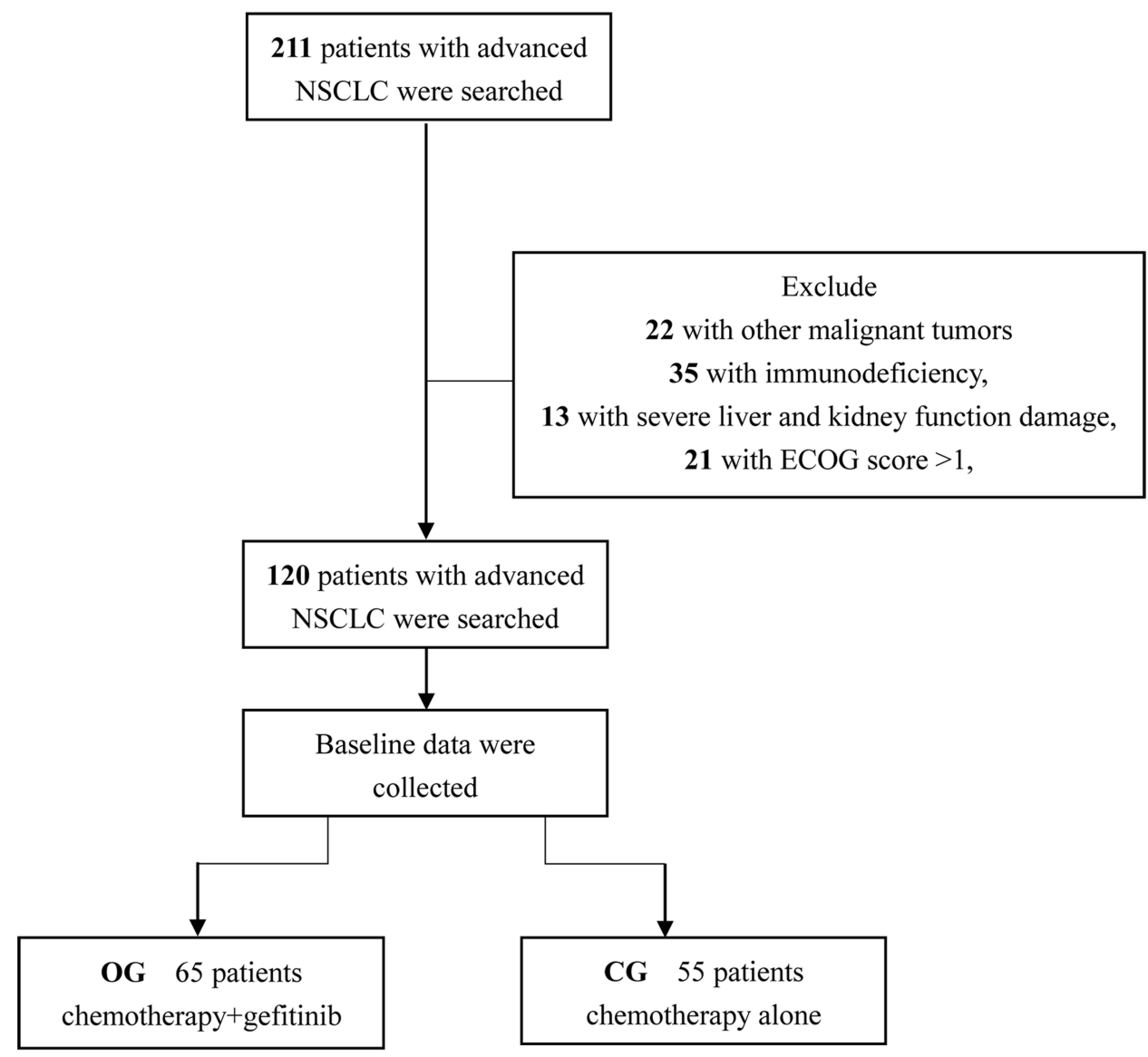

Figure I The flow diagram of patients' enrollment.

of treatment. OG was additionally treated with gefitinib tablets (AstraZeneca, UK, H20090759 $0.25 \mathrm{~g} /$ tablet) orally once a day for 3 weeks. The clinician develops the treatment based on the severity of the patient's condition.

\section{Follow-Up Method}

Follow-up appointments were conducted every 3-4 months during the 2 years through telephone consultation and hospital visits.

\section{Observation Index}

Main outcome measures: Based on the routine examination of patients before the standard treatment and on the RECIST standard customized by the American Cancer Institute, changes in the patient's condition were divided into four phases: complete response (CR), partial response $(\mathrm{PR})$, stable disease (SD), and progression of disease (PD). The patient's ORR was calculated $[\mathrm{ORR}=(\mathrm{CR}+\mathrm{PR}) /$ total number of people], and the patient's DCR was also calculated $[\mathrm{DCR}=(\mathrm{CR}+\mathrm{PR}+\mathrm{SD}) /$ total number of people $]$. We also analyzed the risk factor according to the clinical data using the Cox regression analysis.

Secondary observations: PFS (from the beginning of treatment to the occurrence of secondary growth events); OS (from the beginning of treatment to the death for any cause); and toxicity and adverse effects were monitored during the whole duration of treatment.

\section{Statistical Analysis}

In this study, the collected data were statistically analyzed using SPSS20.0 software package (Guangzhou Bomai), and the data were extracted using GraphPad Prism 7 (Shanghai Bekaa). The count data were represented as rate $(\%)$, and the Chi-square test was used. Measurement data were expressed as mean \pm standard deviation (mean $\pm \mathrm{SD}$ ), and the measurement data between the two groups in accordance with the normal distribution were analyzed using $t$-test. Kaplan-Meier survival curve was also prepared to clarify the survival of patients, while the assessment of other data was 
Table I Assignment Table

\begin{tabular}{|l|l|}
\hline Factor & Assignment \\
\hline Sex & $0=$ Female, I=Male \\
Age & $0=\geq 65$ years, I=<65 years \\
Pathological type & $0=$ Squamous cell carcinoma, \\
& $\mathrm{I}=$ Adenocarcinoma \\
Clinical stages & $0=$ stage III, I=stage IV \\
Brain metastases & $0=$ Yes, I=No \\
Smoking history & $0=$ Yes, I=No \\
EGFR mutation & $0=Y e s, I=N o$ \\
Body weight change & $0 \leq 5 \%, I=\leq 5 \%$ \\
ECOG score & $0=0, I=I$ \\
\hline
\end{tabular}

Abbreviations: EGFR, epidermal growth factor receptor; ECOG, Eastern Cooperative Oncology Group.

compared with the Log rank test. For risks affecting the prognosis, the Cox regression analysis was carried out. The assignment table is shown in Table 1. A statistical difference was observed with $\mathrm{P}<0.05$.

\section{Results}

\section{Clinical Data Analysis of the Two Groups}

The clinical data did not differ significantly between CG and $\mathrm{OG}$, indicating the two groups were comparable $(\mathrm{P}>0.05)$ (Table 2).

\section{Comparison of the Efficacy Between the Two Groups}

The chemotherapy and gefitinib treatment improved the DCR better than chemotherapy alone, as evidenced by data in Table 3. However, two groups showed no significant difference in ORR of OG (36.92\%) and CG (29.09\%) (P>0.05).

\section{PFS and OS in Both Groups}

The chemotherapy and gefitinib treatment greatly improved the medians of PFS and OS than chemotherapy alone (Figures 2, 3 and Table 4).

Table 2 Analysis of the Clinical Data of Patients in the Two Groups [n (\%)]

\begin{tabular}{|c|c|c|c|c|c|}
\hline Factor & & Control Group $(n=55)$ & Observation Group (n=65) & $x^{2}$ & P-value \\
\hline Sex & $\begin{array}{l}\text { Female } \\
\text { Male }\end{array}$ & $\begin{array}{l}40(72.73) \\
15(27.27)\end{array}$ & $\begin{array}{l}52(80.00) \\
13(20.00)\end{array}$ & 0.881 & 0.348 \\
\hline Age & $\begin{array}{l}\geq 65 \text { years } \\
<65 \text { years }\end{array}$ & $\begin{array}{l}39(70.91) \\
16(29.09)\end{array}$ & $\begin{array}{l}48(73.85) \\
17(26.15)\end{array}$ & 0.129 & 0.720 \\
\hline Pathological type & $\begin{array}{l}\text { Squamous cell carcinoma } \\
\text { Adenocarcinoma }\end{array}$ & $\begin{array}{l}50(90.91) \\
5(9.09)\end{array}$ & $\begin{array}{l}57(87.69) \\
8(12.31)\end{array}$ & 0.319 & 0.572 \\
\hline Clinical stages & $\begin{array}{l}\text { IIIA } \\
\text { IIIB } \\
\text { IIV }\end{array}$ & $\begin{array}{l}10(18.18) \\
18(32.73) \\
27(49.09)\end{array}$ & $\begin{array}{l}8(12.31) \\
12(18.46) \\
45(69.23)\end{array}$ & 5.124 & 0.077 \\
\hline Brain metastases & $\begin{array}{l}\text { Yes } \\
\text { No }\end{array}$ & $\begin{array}{l}8(14.55) \\
47(85.45)\end{array}$ & $\begin{array}{l}15(23.08) \\
50(76.92)\end{array}$ & 1.400 & 0.237 \\
\hline Smoking history & $\begin{array}{l}\text { Yes } \\
\text { No }\end{array}$ & $\begin{array}{l}42(76.36) \\
13(23.64)\end{array}$ & $\begin{array}{l}56(86.15) \\
9(13.85)\end{array}$ & 1.907 & 0.167 \\
\hline EGFR mutation & $\begin{array}{l}\text { Yes } \\
\text { No }\end{array}$ & $\begin{array}{l}40(72.73) \\
15(27.27)\end{array}$ & $\begin{array}{l}55(84.62) \\
10(15.38)\end{array}$ & 2.553 & 0.110 \\
\hline Body weight change & $\begin{array}{l}>5 \% \\
\leq 5 \%\end{array}$ & $\begin{array}{l}10(18.18) \\
45(81.82)\end{array}$ & $\begin{array}{l}16(24.62) \\
49(75.38)\end{array}$ & 0.727 & 0.394 \\
\hline ECOG score & $\begin{array}{l}0 \\
1\end{array}$ & $\begin{array}{l}16(29.09) \\
39(70.91)\end{array}$ & $\begin{array}{l}22(33.85) \\
43(66.15)\end{array}$ & 0.311 & 0.577 \\
\hline
\end{tabular}

Abbreviations: EGFR, epidermal growth factor receptor; ECOG, Eastern Cooperative Oncology Group. 
Table 3 Short-Term Efficacy in the Two Groups [n (\%)]

\begin{tabular}{|l|l|l|l|l|l|l|}
\hline Group & CR & PR & SD & PD & ORR & DCR \\
\hline Control group $(n=55)$ & $7(12.73)$ & $9(16.36)$ & $24(43.64)$ & $15(27.27)$ & $29.09 \%$ \\
Observation group $(n=65)$ & $9(13.85)$ & $15(23.08)$ & $33(50.77)$ & $8(12.31)$ & $36.92 \%$ & $72.73 \%$ \\
$X^{2}$ & & & & & 0.822 & 2.075 \\
P-value & & & & & 0.365 \\
\hline
\end{tabular}

Abbreviations: CR, complete response; PR, partial response; SD, stable disease; PD, progression of disease; ORR, objective response rate; DCR, disease control rate.

\section{Cox Regression Analysis}

Clinical data of patients for the univariate analysis was collected and found that the clinical stage of patients (HR $=1.590,95 \%$ CI: 1.097-2.343) was a significant prognostic factor associated with advanced lung cancer. Subsequent multivariate Cox regression analysis revealed that the clinical stage was independent of the patients $(\mathrm{HR}=1.701,95 \%$ CI: 1.099-2.632) (Table 5).

\section{Adverse Effects in the Two Groups During Treatment}

No difference was observed in the total incidence of side effects between CG (58.18\%) and OG (61.54\%) $\left(\mathrm{X}^{2}=0.140, \mathrm{P}=0.708\right)$ (Table 6).

\section{Discussion}

With the development of the society, most countries worldwide have entered the period of industrial advancements, and haze problem and air pollution have become increasingly serious, leading to a gradual increase in morbidity and mortality rates. ${ }^{12}$ In China, research ${ }^{13}$ shows that in 2015 , there

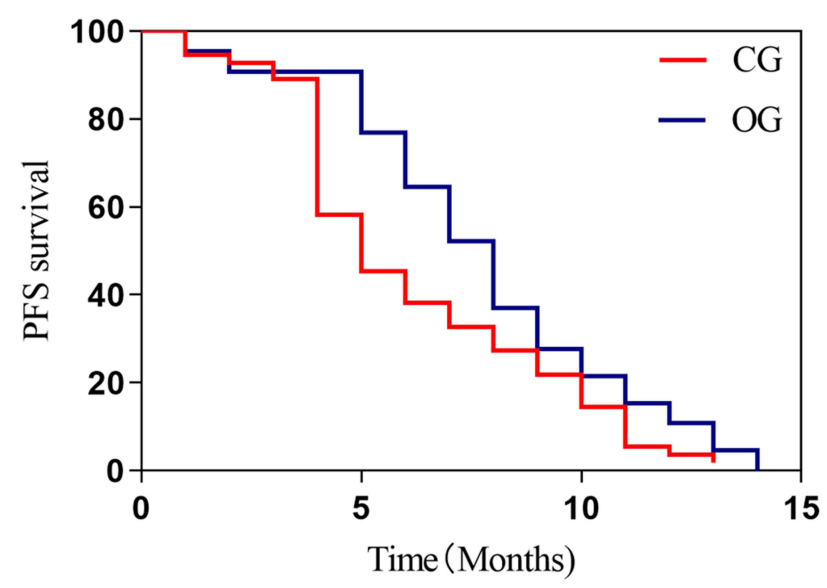

Figure 2 Two groups of patients with PFS. The Log rank test was used for evaluating the PFS and found that the median survival (8 months) in OG was significantly higher than those (5 months) in CG, with statistical difference $(\mathrm{P}=0.017)$.

Abbreviations: PFS, progression-free survival; CG, control group; OG, observation group. were over 733,300 new cases of lung cancer, and more than 610,200 people died of the lung cancer, threatening the safety of patients. Currently, radical resection has become the main treatment method of lung cancer, but the early stage of cancer is generally asymptomatic, making diagnosis difficult. When patients were admitted to the hospital, the condition was basically in the middle and late stages. During this time, the patients had lost the best treatment opportunity, and for these patients, chemo- or radiotherapy remains the most effective methods. Although these methods have made great progress and achievements for these patients, poor prognosis still exists. ${ }^{14}$ Due to the breakthrough for the treatment of cancer in molecular biology, the role of molecular targeted therapy has gradually increased, and the advantages of molecularly targeted drugs with good efficacy and less toxic side effects have gradually popularized in the clinical practice. ${ }^{15}$

Targeted therapy first requires patients to use tumorrelated predictions and biomarker screening to better select the best treatments. In the recent years, EGFRTKI has completely changed the treatment strategy of EGFR-mutant lung cancer, while gefitinib, as an

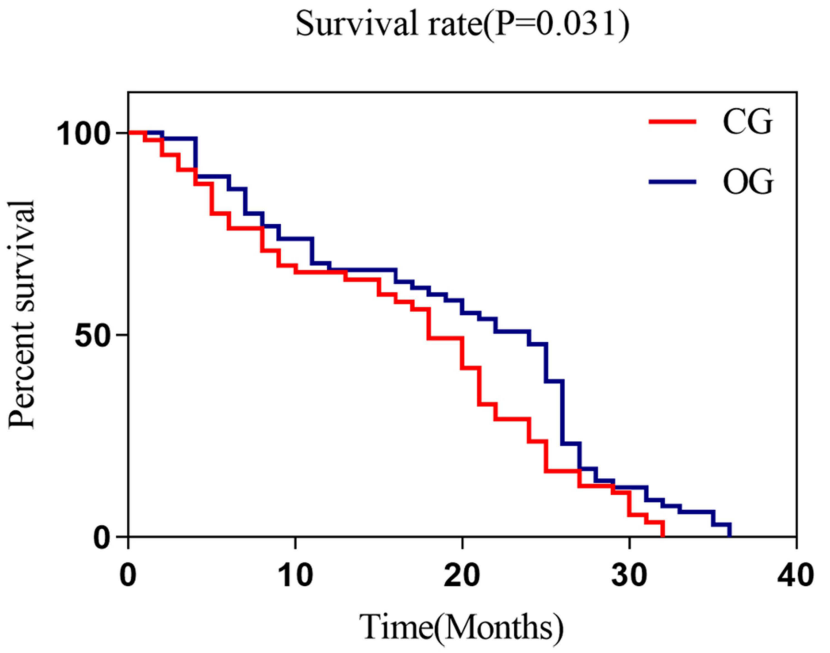

Figure 3 OS states of the two groups of patients. The Log rank test was used for comparing OS between the two groups and found that the median survival time of OS in CG (I8.0 months) was lower than that in OG ( 24 months) $(P=0.03 \mathrm{I})$. Abbreviations: OS, overall survival; CG, control group; OG, observation group. 
Table 4 Comparison of PFS and OS in the Two Groups

\begin{tabular}{|l|l|l|l|l|}
\hline & Median Survival Time in Control Group & Median Survival Time in Observation Group & $\boldsymbol{X}^{2}$ & $\mathbf{P}^{2}$-value \\
\hline PFS (months) & 5.0 & 8.0 & 5.660 & 0.017 \\
OS (months) & 18.0 & 24.0 & 4.678 & 0.031 \\
\hline
\end{tabular}

Abbreviations: PFS, progression-free survival; OS, overall survival.

Table 5 Univariate and Multivariate Cox Regression Analyses

\begin{tabular}{|l|l|l|l|l|}
\hline \multirow{2}{*}{ Factor } & \multicolumn{2}{|l|}{ Univariate } & \multicolumn{2}{l|}{ Multivariate } \\
\cline { 2 - 5 } & $X^{2}$ & P-value & HR (95\% Cl) \\
\hline Sex (M vs F) & 0.169 & 0.681 & - & - \\
Age ( $\geq 65$ vs $<65)$ & 0.879 & 0.348 & - & - \\
Pathological type (squamous cell carcinoma vs adenocarcinoma) & 0.135 & 0.713 & - & - \\
Clinical staging (stage III vs IV) & 5.497 & 0.019 & $1.701(1.099-2.632)$ & - \\
Brain metastasis (yes vs no) & 0.027 & 0.068 & - & - \\
History of smoking (yes vs no) & 0.764 & 0.382 & - & - \\
EGFR mutation (yes vs no) & 1.134 & 0.287 & - & - \\
Body weight change (>5\% vs $\leq 5 \%)$ & 0.004 & 0.947 & - & - \\
ECOG score (0 vs I) & 0.068 & 0.795 & - & - \\
\hline
\end{tabular}

Abbreviations: EGFR, epidermal growth factor receptor; ECOG, Eastern Cooperative Oncology Group; $\mathrm{HR}$, hazard ratio; $\mathrm{Cl}$, confidence interval.

Table 6 Side Effects of Patients in Both Groups [n (\%)]

\begin{tabular}{|l|l|l|l|l|l|}
\hline Group & Erythra & Diarrhoea & Arthralgia & Leukocytopenia & Platelet Depression \\
\hline Control group $(n=55)$ & $3(5.45)$ & $9(16.36)$ & $8(14.55)$ & $5(9.09)$ & $7(12.73)$ \\
Observation group $(n=65)$ & $4(6.15)$ & $10(15.38)$ & $11(16.92)$ & $7(10.77)$ & $8(12.31)$ \\
\hline
\end{tabular}

important member of EGFR-TKI, has an obvious curative effect. ${ }^{16}$ However, long-term use of EGFR-TKI can lead to drug resistance, usually with new progress during the $7-12$ months of treatment. ${ }^{17}$ Drug resistance can be divided into primary and acquired drug resistance after the targeted therapy based on the mode of acquisition. Most patients are treated with targeted therapy or acquired resistance. ${ }^{18}$ The common clinical resistance mechanism is due to EGFR 20 exon mutation (T790M), which leads to changes in the structure of methionine replaced by threonine, thereby increasing the affinity with ATP, and finally acquiring resistance to TKI through the competitive reduction of the TKI and ATP affinity. ${ }^{19}$

Gefitinib, an important EGFR-TKI inhibitor, can significantly inhibit tumor proliferation and growth by inhibiting EGFR tyrosine kinase activity and can promote tumor cell apoptosis. $^{20} \mathrm{~A}$ study $^{21}$ has shown that gefitinib can effectively inhibit a variety of tumor cell lines xenografted in nude mice and can also improve the antitumor effects of chemotherapy and radiotherapy. The clinical study of He et $\mathrm{al}^{22}$ showed that these patients were significantly and effectively treated with gefitinib, and the disease-related symptoms were significantly improved, which improves the quality of life. However, drug resistance is also predictable in long-term use. New drugs for TKI resistance are still in the stage of research and development and clinical trials, and only a small number of people can participate in this research. ${ }^{23}$ Therefore, patients still need to return to the treatment of existing drugs after drug resistance. At present, chemotherapy and EGFR-TKI combined with chemotherapy are frequently used. Therefore, the first-line treatment for patients with NSCLC developed resistant EGFR mutations using gefitinib was explored, and the choice of treatment options for clinicians was compared, so as to provide a reference treatment option.

This study also analyzed the treatment status of the two groups based on different treatment options of the 
patients. Results showed that no statistically significant difference was found in the ORR of CG (29.09\%) and OG $(36.92 \%)$. In the study of Yang et al, ${ }^{24}$ it showed that no difference in the ORR was observed between advanced lung cancer patients only treated with chemotherapy and those with chemotherapy combined with gefitinib, which indicated that the ORR between them was basically the same. Moreover, the patient's DCR was compared and found that it was higher in OG $(87.69 \%)$ than that in $\mathrm{CG}(72.73 \%)$. The toxic side effects between the two groups of patients were also compared and found that the incidence of toxicity and side effects was similar between the two groups, which may indicate that gefitinib combined with chemotherapy is significantly effective to control the disease. During the study, we followed up the two groups of patients, analyzed their PFS and OS states, and plotted the survival curve. Results showed that the median time of PFS was different between $\mathrm{CG}$ and $\mathrm{OG}$ at 8 months and 5 months, respectively. We also calculated the total survival time of patients and found that those of $\mathrm{OG}$ were higher than those of $\mathrm{CG}$, indicating that chemotherapy and gefitinib prolong the survival of NSCLC patients carrying EGFR-mutation in advanced stage. We conducted a Cox regression analysis and determined that clinical stage is an independent factor in evaluating the prognosis. However, there remain some limitations. First, the number of samples is small. Second, this is a retrospective study. Whether the difference in the statistical results is important remains to be continuously explored. Therefore, future research should be conducted on a large sample size, and randomized and multi-blind experiments should be conducted to verify the results of this study.

\section{Conclusion}

Clinical staging was an independent prognostic factor for patients with advanced EGFR-mutation in NSCLC. For those patients, during the first-line treatment, the effects of gefitinib combined with chemotherapy were significantly better than those of chemotherapy alone. In patients with PFS, the OS rate was significantly improved in the clinical setting.

\section{Disclosure}

The authors report no conflicts of interest for this work.

\section{References}

1. Siegel RL, Miller KD, Jemal A. Cancer statistics, 2016. CA Cancer $J$ Clin. 2016;66(1):7-30. doi:10.3322/caac.21332

2. DeSantis CE, Siegel RL, Sauer AG, et al. Cancer statistics for African Americans, 2016: progress and opportunities in reducing racial disparities. CA Cancer J Clin. 2016;66(4):290-308. doi:10.3322/caac. 21340

3. Rizvi NA, Hellmann MD, Snyder A, et al. Cancer immunology. Mutational landscape determines sensitivity to PD-1 blockade in non-small cell lung cancer. Science. 2015;348(6230):124-128. doi:10.1126/science.aaa1348

4. Brahmer J, Reckamp KL, Baas P, et al. Nivolumab versus docetaxel in advanced squamous-cell non-small-cell lung cancer. $N$ Engl $J$ Med. 2015;373(2):123-135. doi:10.1056/NEJMoa1504627

5. Reck M, Rodriguez-Abreu D, Robinson AG, et al. Pembrolizumab versus Chemotherapy for PD-L1-positive non-small-cell lung cancer. $N$ Engl J Med. 2016;375(19):1823-1833. doi:10.1056/ NEJMoa 1606774

6. Wu YL, Zhou C, Hu CP, et al. Afatinib versus cisplatin plus gemcitabine for first-line treatment of Asian patients with advanced non-small-cell lung cancer harbouring EGFR mutations (LUX-Lung 6): an open-label, randomised Phase 3 trial. Lancet Oncol. 2014;15(2):213-222. doi:10.1016/S1470-2045(13)70604-1

7. Solomon BJ, Mok T, Kim DW, et al. First-line crizotinib versus chemotherapy in ALK-positive lung cancer. $N$ Engl $J$ Med. 2014;371(23):2167-2177. doi:10.1056/NEJMoa1408440

8. Morin-Ben AS, Hirsh V. Epidermal growth factor receptor tyrosine kinase inhibitors in treatment of metastatic non-small cell lung cancer, with a focus on afatinib. Front Oncol. 2017;7:97. doi:10.3389/ fonc. 2017.00097

9. Jones HE, Gee JM, Barrow D, Tonge D, Holloway B, Nicholson RI. Inhibition of insulin receptor isoform-A signalling restores sensitivity to gefitinib in previously de novo resistant colon cancer cells. $\mathrm{Br}$ $J$ Cancer. 2006;95(2):172-180. doi:10.1038/sj.bjc.6603237

10. Yang JJ, Zhou Q, Yan HH, et al. A phase III randomised controlled trial of erlotinib vs gefitinib in advanced non-small cell lung cancer with EGFR mutations. $B r \quad J$ Cancer. 2017;116(5):568-574. doi:10.1038/bjc.2016.456

11. Allen PJ, Kuk D, Castillo CF, et al. Multi-institutional Validation Study of the American Joint Commission on Cancer (8th Edition) Changes for $\mathrm{T}$ and $\mathrm{N}$ Staging in Patients With Pancreatic Adenocarcinoma. Ann Surg. 2017;265(1):185-191. doi:10.1097/ SLA.0000000000001763

12. Ferlay J, Soerjomataram I, Dikshit R, et al. Cancer incidence and mortality worldwide: sources, methods and major patterns in GLOBOCAN 2012. Int $J$ Cancer. 2015;136(5):E359-E386. doi:10.1002/ijc. 29210

13. Chen W, Zheng R, Baade PD, et al. Cancer statistics in China, 2015. CA Cancer J Clin. 2016;66(2):115-132. doi:10.3322/caac.21338

14. Tran L, Xiao JF, Agarwal N, Duex JE, Theodorescu D. Advances in bladder cancer biology and therapy. Nat Rev Cancer. 2021;21 (2):104-121. doi:10.1038/s41568-020-00313-1

15. Xia W, Tao Z, Zhu B, et al. Targeted delivery of drugs and genes using polymer nanocarriers for cancer therapy. Int J Mol Sci. 2021;22 (17):9118. doi:10.3390/ijms22179118

16. Han R, Jia Y, Li X, et al. Concurrent use of metformin enhances the efficacy of EGFR-TKIs in patients with advanced EGFR-mutant non-small cell lung cancer-an option for overcoming EGFR-TKI resistance. Transl Lung Cancer Res. 2021;10(3):1277-1291. doi: $10.21037 /$ tlcr-20-1153

17. Chan O, Lam KC, Li J, et al. ATOM: a Phase II study to assess efficacy of preemptive local ablative therapy to residual oligometastases of NSCLC after EGFR TKI. Lung Cancer. 2020;142:41-46. doi:10.1016/j.lungcan.2020.02.002 
18. Schoenfeld AJ, Hellmann MD. Acquired Resistance to Immune Checkpoint Inhibitors. Cancer Cell. 2020;37(4):443-455. doi:10.1016/j.ccell.2020.03.017

19. Dong RF, Zhu ML, Liu MM, et al. EGFR mutation mediates resistance to EGFR tyrosine kinase inhibitors in NSCLC: from molecular mechanisms to clinical research. Pharmacol Res. 2021;167:105583. doi:10.1016/j.phrs.2021.105583

20. Li A, Cao W, Liu X, et al. Gefitinib sensitization of cisplatin-resistant wild-type EGFR non-small cell lung cancer cells. J Cancer Res Clin Oncol. 2020;146(7):1737-1749. doi:10.1007/s00432-020-03228-4

21. Tang N, Zhang Q, Fang S, Han X, Wang Z. Anti-tumor activity of high-dose EGFR tyrosine kinase inhibitor and sequential docetaxel in wild type EGFR non-small cell lung cancer cell nude mouse xenografts. Oncotarget. 2017;8(6):9134-9143. doi:10.18632/ oncotarget. 13327
22. He J, Su C, Liang W, et al. Icotinib versus chemotherapy as adjuvant treatment for stage II-IIIA EGFR-mutant non-small-cell lung cancer (EVIDENCE): a randomised, open-label, phase 3 trial. Lancet Respir Med. 2021;9(9):1021-1029. doi:10.1016/S2213-2600(21)00134-X

23. Wu L, Ke L, Zhang Z, Yu J, Meng X. Development of EGFR TKIs and Options to Manage Resistance of Third-Generation EGFR TKI Osimertinib: conventional Ways and Immune Checkpoint Inhibitors. Front Oncol. 2020;10:602762. doi:10.3389/fonc.2020.602762

24. Yang JC, Srimuninnimit V, Ahn MJ, et al. First-line pemetrexed plus cisplatin followed by gefitinib maintenance therapy versus gefitinib monotherapy in east asian never-smoker patients with locally advanced or metastatic nonsquamous non-small cell lung cancer: final overall survival results from a Randomized Phase 3 Study. J Thorac Oncol. 2016;11(3):370-379. doi:10.1016/j.jtho.2015.11.008

\section{Publish your work in this journal}

The International Journal of General Medicine is an international, peer-reviewed open-access journal that focuses on general and internal medicine, pathogenesis, epidemiology, diagnosis, monitoring and treatment protocols. The journal is characterized by the rapid reporting of reviews, original research and clinical studies across all disease areas. The manuscript management system is completely online and includes a very quick and fair peer-review system, which is all easy to use. Visit http://www.dovepress.com/ testimonials.php to read real quotes from published authors. 